\title{
EBV-negative aggressive NK-cell leukemia/ lymphoma: a clinical and pathological study from a single institution
}

\author{
Juehua Gao ${ }^{1}$, Amir Behdad ${ }^{1}$, Peng Ji ${ }^{1}$, Kristy L Wolniak ${ }^{1}$, Olga Frankfurt ${ }^{2}$ and Yi-Hua Chen ${ }^{1}$ \\ ${ }^{1}$ Division of Hematopathology, Department of Pathology, Northwestern University Feinberg School of \\ Medicine, Chicago, IL, USA and ${ }^{2}$ Division of Hematology-Oncology, Department of Medicine, Northwestern \\ University Feinberg School of Medicine, Chicago, IL, USA
}

\begin{abstract}
Aggressive natural killer (NK)-cell leukemia/lymphoma is a systemic NK-cell neoplasm that preferentially affects Asians with a fulminant clinical course and is almost always associated with Epstein-Barr virus (EBV). The data on EBV-negative aggressive NK-cell leukemia/lymphoma are limited. Here we report a series of three patients (two Caucasians, one African-American) with EBV-negative aggressive NK-cell leukemia/lymphoma from a single institution, including a case diagnosed on post-mortem examination. Similar to EBV-positive aggressive NK-cell leukemia/lymphoma, our patients presented with constitutional symptoms and hepatosplenomegaly, and followed a highly aggressive clinical course. The disease involved peripheral blood, bone marrow, liver, spleen, and lymph node, and the neoplastic cells were pleomorphic with prominent azurophilic granules and demonstrated an atypical NK-cell phenotype. Lack of blood lymphocytosis (3 of 3), bone marrow interstitial infiltration (2 of 3), EBER negativity (3 of 3), and atypical phenotype including CD3 negativity by immunohistochemistry make an early recognition of the disease difficult. Ancillary studies revealed a complex karyotype (1 of 2), overexpression (3 of 3), and amplification (1 of 1) of $c-M Y C$. The polycomb repressive complex 2 pathwayassociated proteins EZH2 and H3K27me3 and immune checkpoint protein PD-L1 were overexpressed in three of three and two of three cases, respectively. Our findings indicate that the EBV-negative aggressive NK-cell leukemia/lymphoma shares similar clinicopathological features to the EBV-positive counterpart except for the high prevalence of Asian seen in EBV-positive cases. Overexpression of polycomb repressive complex 2 pathway-associated proteins and PD-L1 suggest potential therapeutic targets for this aggressive disease. Nextgeneration sequencing on two of three cases identified multiple genetic alterations but were negative for JAKSTAT pathway-associated gene mutations previously reported in EBV-positive NK/T-cell lymphoma, suggesting alternative molecular pathogenic mechanisms for EBV-negative aggressive NK-cell leukemia/lymphoma. Modern Pathology (2017) 30, 1100-1115; doi:10.1038/modpathol.2017.37; published online 26 May 2017
\end{abstract}

Aggressive natural killer (NK)-cell leukemia/lymphoma is a systemic neoplastic proliferation of NK cells that most commonly involves peripheral blood, bone marrow, liver, and spleen. Aggressive NK-cell leukemia/lymphoma has a highly aggressive clinical course and is often associated with multiorgan failure and hemophagocytic syndrome with a median survival of 2 months. ${ }^{1}$ Aggressive NK-cell leukemia/lymphoma is characteristically associated with Epstein-Barr virus (EBV), and EBER positivity

Correspondence: Dr J Gao, MD, PhD, Department of Pathology, Northwestern University Feinberg School of Medicine, Feinberg Pavilion 7-209A, 251 East Huron Street, Chicago, IL 60611, USA. E-mail: j-gao@northwestern.edu

Received 9 February 2017; revised 13 March 2017; accepted 15 March 2017; published online 26 May 2017 serves as an important diagnostic criteria for this entity. The data on EBV-negative aggressive NK-cell leukemia/lymphoma are limited. To the best of our knowledge, there have been 16 cases reported in the English literature, ${ }^{2-9}$ often as single case reports or rare exceptions included in the studies of EBVpositive aggressive NK-cell leukemia/lymphoma. ${ }^{2-8}$ A recent study of a series of seven cases has shown that the EBV-negative aggressive NK-cell leukemia/ lymphoma is indistinguishable clinically and pathologically from EBV-positive counterpart, ${ }^{9}$ in contrast to some earlier reports suggesting that patients with EBV-negative aggressive NK-cell leukemia/lymphoma have a less aggressive clinical course and more favorable response to treatment. ${ }^{2,5,7}$

Most of the studies on the pathogenesis of NK/ T-cell lymphomas were on extranodal NK/T-cell 
lymphoma, nasal type, or its cell line derivative, with very limited information on aggressive NK-cell leukemia/lymphoma. ${ }^{10-12}$ Gene expression profiling of EBV-associated nasal-type NK/T-cell lymphoma identified a number of genes differentially expressed in the tumor cells, one of which encodes enhancer of zeste homolog 2 (EZH2), a trimethylated histone H3 lysine residue 27 (H3K27)-specific histone methyltransferase. EZH2 is a key component of the polycomb repressive complex 2 (PRC2) pathway, ${ }^{11}$ and overexpression of EZH2 in nasal NK/T-cell lymphoma confers a growth advantage that is found to be mediated by $M Y C$-induced micro RNAs. ${ }^{12}$ Recently, overexpression of PRC2 pathwayassociated proteins has been found in various types of T- and NK-cell lymphomas, particularly those which are EBV associated, and is highly correlated with overexpression of C-MYC. ${ }^{10,12}$ Recurrent mutations have also been identified in EBVassociated extranodal NK/T-cell lymphomas, and mutations leading to the activation of the JAK-STAT pathway are shown to play a significant role in the pathogenesis of these neoplasms. In a recent study, Nicolae et $a l^{9}$ performed limited sequencing on two cases of EBV-negative aggressive NK-cell leukemia/ lymphoma and found point mutations of STAT3 gene in both cases.

Here we report a series of three cases of EBVnegative aggressive NK-cell leukemia/lymphoma from our institution, including a case diagnosed on post-mortem examination. The clinicopathological features, including clinical presentations and outcomes, morphologic findings of peripheral blood, bone marrow, liver and spleen, immunophenotyping, cytogenetic studies, molecular and fluorescence in situ hybridization (FISH) analyses, were reviewed. Additionally, the expression of the key components of the PRC2 pathway EZH2 and H3K27, the potential activator of the PRC2 pathway c-MYC, and the immune checkpoint protein PD-L1 were also examined. We also performed next-generation sequencing using a comprehensive panel to evaluate potential molecular pathways involved in EBV-negative aggressive NK-cell leukemia/lymphoma pathogenesis.

\section{Materials and methods}

\section{Case Selection}

This study was approved by the Institutional Review Board of Northwestern University. Three cases that

Table 1 Clinical features of EBV-negative aggressive NK cell leukemia/lymphoma

\begin{tabular}{|c|c|c|c|}
\hline & Patient 1 & Patient 2 & Patient 3 \\
\hline Age/sex/race & 67/M/Caucasian & 48/M/African-American & 88/F/Caucasian \\
\hline Clinical history & $\begin{array}{l}\text { Beta thalassemia trait; celiac } \\
\text { disease; follicular thyroid } \\
\text { carcinoma status post total } \\
\text { thyroidectomy and radioactive } \\
\text { ablation; renal cell carcinoma } \\
\text { status post partial right } \\
\text { nephrectomy; celiac disease. }\end{array}$ & Type 2 diabetes & $\begin{array}{l}\text { Chronic myelogenous leukemia; } \\
\text { breast carcinoma s/p mastectomy }\end{array}$ \\
\hline Initial presentation & Fever, night sweats & Fever, night sweats & Abdominal pain \\
\hline \multicolumn{4}{|l|}{ Radiologic findings } \\
\hline Splenomegaly & Marked, with mass lesions & Marked & Marked \\
\hline Hepatomegaly & No & Mild & Marked \\
\hline Lymphadenopathy & Mild & Mild & Mild \\
\hline Others & Multiple lung lesions & No & No \\
\hline \multicolumn{4}{|c|}{ Laboratory findings at initial presentation } \\
\hline Anemia & Mild (11 g/dl) & Moderate (10.2 g/dl) & Mild (11.1 g/dl) \\
\hline Neutropenia & Yes $(1.3 \mathrm{k} / \mu \mathrm{L})$ & Yes $(1.2 \mathrm{k} / \mu \mathrm{l})$ & No $(6.0 \mathrm{k} / \mu \mathrm{l})$ \\
\hline Lymphocytosis & No $(0.3 \mathrm{k} / \mu \mathrm{l})$ & No $(0.9 \mathrm{k} / \mu \mathrm{l})$ & No $(0.4 \mathrm{k} / \mu \mathrm{l})$ \\
\hline Thrombocytopenia & Yes $(36 \mathrm{k} / \mu \mathrm{l})$ & Yes $(47 \mathrm{k} / \mu \mathrm{l})$ & Yes $(104 \mathrm{k} / \mu \mathrm{l})$ \\
\hline LDH & Elevated (2083 U/l) & Elevated (748 U/l) & NA \\
\hline EBV serology & Negative & Negative & NA \\
\hline $\begin{array}{l}\text { Clinical course \& } \\
\text { outcome }\end{array}$ & $\begin{array}{l}\text { Sepsis, respiratory failure, } \\
\text { progressive cytopenias; died on } \\
\text { day } 3 \text { of admission and } 2 \text { weeks } \\
\text { after initial presentation }\end{array}$ & $\begin{array}{l}\text { Hemophagocytic lymphohistiocytosis, } \\
\text { sepsis, progressive cytopenias, acute } \\
\text { kidney injury and respiratory failure; } \\
\text { died in } 3 \text { months after initial } \\
\text { presentation }\end{array}$ & $\begin{array}{l}\text { Multisystem organ failure, } \\
\text { coagulopathy, progressive } \\
\text { cytopenias, metabolic acidosis } \\
\text { and acute kidney injury; died on } \\
\text { day } 7 \text { of admission and } 3 \text { weeks } \\
\text { after initial presentation }\end{array}$ \\
\hline Chemotherapy & No & $\begin{array}{l}\text { Etoposide and dexamethasone for } \\
\text { hemophagocytic lymphohistiocytosis; } \\
\text { EPOCH for lymphoma }\end{array}$ & No \\
\hline
\end{tabular}

Abbreviation: NA, not available. 
fulfilled the diagnostic criteria for aggressive NK-cell leukemia/lymphoma based on the 2008 WHO classification ${ }^{1}$ but were EBER negative were identified and retrieved from the Department of Pathology at Northwestern Memorial Hospital. The available archival materials were reviewed by three hematopathologists (JG, AB and YC), including peripheral blood smear and bone marrow biopsy from patient 1, peripheral blood smear, bone marrow biopsy, and liver biopsy from patient 2 , and tissues obtained at autopsy, including vertebral bone with bone marrow component, liver, spleen, lymph node, from patient 3 (Table 1). The associated ancillary studies, including immunohistochemical stains performed at the time of diagnosis, flow cytometric analysis on the peripheral blood and/or bone marrow aspirate and molecular analysis, were also reviewed. Additional immunohistochemical stains, molecular and FISH analysis were performed in this study and are further described.

\section{Immunohistochemistry}

Imunohistochemical stains were performed on the bone marrow core biopsy (cases 1 and 2), liver core biopsy (case 2), and bone marrow, liver, and spleen tissues from autopsy (case 3). Immunohistochemical stains were performed on automated Ventana Benchmark (Ventana System, Tucson, AZ, USA) with the following antibodies: CD45 (dilution 1:300, clone: 2B11+PD7/26; Dako), CD30 (clone: Ber-H2; Dako), TIA1 (dilution 1:150, clone: 2G9A10F5; Beckman Coulter), predilute CD3 (clone: LN10; Leica), CD20 (dilution 1:1000, clone: L26; Dako), PAX5 (dilution 1:10, clone: SP34; Cell Marque), CD8 (dilution 1:40, clone: C8/144B; Dako), CD15 (dilution 1:20, clone: MMA; Becton Dickenson), CD2 (dilution 1:20, clone: AB75; Leica), CD5 (dilution 1:40, clone: 4C7; Leica), predilute CD7 (clone: LP15; Leica), TCR $\gamma$ (clone: ช3.20; Thermo Fisher Scientific), EBER (predilute Eber 1 DNP Probe; Ventana). Immunohistochemical stains were performed on automated Leica Bond Max (Leica Microsystems, Buffalo Grove, IL, USA) using the Bond polymer refine detection HRP (Leica Biosystems, DS9800) method with the following antibodies: predilute CD56 (clone: CD564; Leica), predilute CD4 (clone: 4B12; Leica), $\beta \mathrm{F} 1$ (dilution 1:40, clone: 8A3; Thermo Fisher), PD-L1 (dilution 1:50, clone: SP142S; Spring Bioscience), EZH2 (clone: 11/EZH2; BD Bioscience), and H3K27me3 (clone: MABI 0323; Active Motif), MLH1 (clone ES05; Leica), MSH2 (clone G219-1129; Cell Marque), MSH6 (clone: 44 Mab; Cell Marque), PMS2 (clone MRQ-28; Cell Marque).

\section{Flow Cytometric Immunophenotyping}

Flow cytometric analysis was performed on the bone marrow aspirate (case 1) and peripheral blood sample (case 2). Data collection was performed on a Becton Dickinson Biosciences (BD, Franklin Lakes,
NJ, USA) FACSCanto II flow cytometer. Data analysis was performed using FACSDiva software (BD). The following antibodies were used to access $\mathrm{T}$ and $\mathrm{NK}$ cells: CD3 PerCP-Cy5.5 (BD, clone SK7), CD2 PC7 (Beckman Coulter, clone 39C1.5), CD5 APC (BD, clone L17F12), CD7 PE (Immunotech, clone 8H8.1), CD4 FITC (Beckman Coulter clone SFCI12T4D11), CD8 APC-H7 (BD, clone SKI), CD57 FITC (Beckman Coulter, clone NCI), CD56 PE-Cy7 (Beckman Coulter, clone NKH-1), CD16 PE (BD, clone B73.1), TIA1 PE (Beckman Coulter, clone 2G9A10F5), granzyme B FITC (BD, clone GB11), perforin FITC (BD Pharmingen, clone $\delta \mathrm{G} 9$ ), TCR $\alpha \beta$ (BD, clone WT31), TCR $\gamma \delta$ (BD, clone 11F2), CD158a APC (Beckman Coulter, clone EB6B), CD158b FITC (BD, clone CH-L) and CD158e PE (Beckman Coulter, clone Z27.3.7).

\section{Molecular Analysis for T-Cell Receptor Gene Rearrangement}

The PCR was performed to assess T-cell receptor (TCR) gamma chain gene rearrangement using the Invivoscribe TCR $\gamma$ chain clonality assay (Invivoscribe Technologies, San Diego, CA, USA) and capillary electrophoresis (ABI 3130-I; Applied Biosystems, Carlsbad, CA, USA) according to the manufacturers' instruction. The PCR products from a clonal T-cell population produce a narrow spike on capillary electrophoresis. A population was considered clonal if the height of the spike was more than three times the height of the third highest peak in a given range of DNA fragment sizes.

\section{Fluorescence In Situ Hybridization}

Interphase FISH for $c-M Y C$ was performed on airdried, unstained bone marrow touch imprints (cases 1 and 2) and paraffin-embedded spleen tissue (case 3), using Vysis dual color break-apart $c-M Y C$ probes (Abbott Molecular, Des Plaines, IL, USA). The 5' and 3' portions of the $c-M Y C$ gene are labeled with SpectrumOrange and SpectrumGreen, respectively. A total of 100 interphase cells were evaluated for $c-M Y C$ alterations independently by two technologists. Rearrangement of $c-M Y C$ is determined if the percentage of cells with abnormal FISH signals, that is, a separation of the $5^{\prime}$ and $3^{\prime} C-M Y C$ probes due to a translocation of the $c-M Y C$ locus, is above the relevant cutoff values at $95 \%$ confidence $(2.1 \%$ in our Cytogenetics Laboratory). Amplification of $c-M Y C$ is defined in this study as $\geq 5$ intact signals in $C-M Y C$ locus. A negative and positive control slides were performed in parallel with the patient sample in the same hybridization process.

\section{Next-Generation Sequencing}

DNA was extracted from air-dried bone marrow aspirate smears in case 1 and paraffin-embedded 
splenic tissue from case 3 . The material was inadequate in case 2 for sequencing. Nextgeneration sequencing was performed using University of Chicago OncoPlus Test. This is a 1212 gene hybrid capture panel that is sequenced on an Illumina HiSeq instrument. The data are analyzed with a custom-developed pipeline that detects point mutations insertion/deletions and copy number variations. The technical details of this assay have been described previously. ${ }^{13}$ The bioinformatics pipeline produces a list of annotated variants that have a depth of read of at least $\times 50$ (with Phred quality score $>30$ ). This pipeline filters out: all variants with frequency $>1 \%$ reported in $1000 \mathrm{Gen}$ ome, exAC (The Exome Aggregation Consortium), and ESP (Exome Sequencing Project) databases; any variants that are in the UTR or upstream/downstream of the gene; variants with a synonymous coding effect and variants within intronic region, unless they result in splice site mutations. The pipeline also is set to filter out variants that have a mutant allele frequency less than $10 \%$; however, if needed the variants with mutant allele frequency less than $10 \%$ can be curated manually, as it was done in this project for the specimen from case 1 which had a tumor burden of $\sim 15 \%$.

\section{Results}

\section{Clinical Information}

Patient 1 was a 67-year-old Caucasian male with a remote history of follicular thyroid carcinoma status post total thyroidectomy and radioactive ablation, celiac disease, $\beta$-thalassemia trait, and a recent diagnosis of stage 1 renal cell carcinoma status post partial right nephrectomy. The patient was admitted with a fever of $102 \mathrm{~F}$ for 10 days, fatigue, and night sweats. Prior to the presentation, he had 3 months of intermitted low-grade fever, leukopenia and thrombocytopenia. Laboratory findings on admission included mild anemia (hemoglobin $11.0 \mathrm{~g} / \mathrm{dl}$; reference range $13.0-17.5 \mathrm{~g} / \mathrm{dl})$, leukopenia with absolute neutropenia (white blood cell count $2.0 \mathrm{k} / \mu \mathrm{l}$; reference range $3.5-10.5 \mathrm{k} / \mu \mathrm{l}$ ), thrombocytopenia (platelet count $36 \mathrm{k} / \mu \mathrm{l}$; reference range $140-390 \mathrm{k} / \mu \mathrm{l}), \quad$ markedly elevated LDH level (2083 U/l; reference range 0-271 U/l), and elevated liver enzymes. The infectious disease work-up during his hospital stay was negative, including cytomegalovirus, EBV, hepatitis viruses, respiratory viral panel and blood cultures. A PEC-CT for staging of renal cell carcinoma revealed marked splenomegaly with hypointense nodules, mild abdominal lymphadenopathy, and new lung nodules, concerning for possible metastatic carcinoma or lymphoma. A bone marrow biopsy was performed during his hospital stay, and revealed involvement by an EBERnegative NK-cell neoplasm (see details in Morphologic Findings). The patient's previous small bowel biopsy for celiac disease was re-reviewed and there was no morphologic or immunophenotypic evidence for T- or NK-cell lymphoma. The patient's clinical condition rapidly deteriorated and he developed sepsis, respiratory failure, and acute hemoglobin drop. The patient died on day 3 of admission (2 weeks after becoming acutely symptomatic).

Patient 2 was a 48-year-old African-American male with a history of type 2 diabetes, who initially presented with fever of unknown origin, night sweats, myalgia, and headache. Laboratory findings at initial presentation included anemia (hemoglobin: $10.2 \mathrm{~g} / \mathrm{dl}$ ), leukopenia with absolute neutropenia (white blood cell count: $2.1 \mathrm{k} / \mu \mathrm{l}$ ), thrombocytopenia (platelet count: $47 \mathrm{k} / \mu \mathrm{l}$ ), and elevated LDH level (748 U/l; reference range 0-271 U/l). Extensive infectious disease work-up during his hospital stay was negative, including blood cultures, respiratory viral panel, serology tests for EBV, cytomegalovirus, and hepatitis viruses. He subsequently developed progressive worsening pancytopenia, acute renal failure, and markedly elevated ferritin, and was diagnosed with hemophagocytic lymphohistiocytosis. CT revealed marked hepatosplenomegaly, mild abdominal lymphadenopathy, and diffuse bone marrow signal abnormalities. A bone marrow biopsy was performed and showed findings consistent with hemophagocytic lymphohistiocytosis. Additionally, an abnormal lymphoid infiltrate was identified in the bone marrow, as well as in a subsequent liver biopsy, morphologically and immunophenotypically consistent with an NK-cell neoplasm that was EBER negative (see details in Morphologic Findings). The patient was treated with Etopside and Dexamethasone for hemophagocytic lymphohistiocytosis, and subsequently treated with EPOCH regimen (etoposide-prednisone-Oncovin-cyclophosphamide-hydroxydaunorubicin) for NK-cell lymphoma; however, he developed worsening cytopenias, severe sepsis, acute kidney injury and respiratory failure, and died in 3 months after the initial presentation.

Patient 3 was an 88-year-old Caucasian female with a prior history of chronic myelogenous leukemia with $\mathrm{t}(9 ; 22) / B C R-A B L 1(\mathrm{p} 210)$, treated with tyrosine kinase inhibitor and in hematologic remission, and breast carcinoma status post mastectomy. The patient presented to the Emergency Department with 2-3 weeks of abdominal pain, decreased appetite, nausea, and weakness. Physical exam revealed hepatosplenomegaly with no peripheral lymphadenopathy, which raised a clinical concern for chronic myelogenous leukemia progression. However, the $B C R-A B L 1$ level remained stable with a value of $4.8 \%$ (IS). The laboratory findings on admission showed mild anemia (hemoglobin $11.1 \mathrm{~g} / \mathrm{dl}$; reference range 11.6-15.4 g/dl), normal white blood cell count, thrombocytopenia (platelet count $104 \mathrm{k} / \mu \mathrm{l}$ ), elevated liver enzymes and alkaline phosphatase, lactic acidosis, and acute kidney injury. A PET-CT scan revealed marked hepatosplenomegaly, heterogeneity of the liver parenchyma with mass lesions, 
and mild abdominal lymphadenopathy. Serology tests for hepatitis viruses and viral culture for cytomegalovirus were negative. The patient's clinical status rapidly decompensated with progressive thrombocytopenia, multisystem organ failure, worsening coagulopathy, worsening metabolic acidosis, and acute kidney injury. The patient died on day 7 of admission. A diagnosis of EBER-negative aggressive NK-cell leukemia/lymphoma was made on postmortem evaluation.

In summary, our three patients had similar clinical presentations, including systemic symptoms (3 of 3), splenomegaly (3 of 3 ), hepatomegaly ( 2 of 3 ), progressive cytopenias (3 of 3 ), highly aggressive clinical course, and fatal outcome (3 of 3). Two patients died within the first week of admission (2-3 weeks after becoming acutely symptomatic), and one patient received therapy for hemophagocytic lymphohistiocytosis and lymphoma but died in 3 months after initial presentation. The clinical features of the three patients are summarized in Table 1.

\section{Morphologic Findings}

The CBC of the three patients at presentation showed mild to moderate anemia ( 3 of 3 ), neutropenia ( 2 of 3 ), and thrombocytopenia ( 3 of 3 ). None of the patients had lymphocytosis; however, abnormal lymphocytes were identified in patients 1 and 2, but only rare atypical lymphocytes were seen in patient 3 on a retrospective review. The abnormal lymphocytes were variable in size ranging from intermediate to large cells with highly irregular nuclei, dense chromatin and pale blue cytoplasm with prominent azurophilic granules, readily recognizable as abnormal large granular lymphocytes (Figure 1). Occasional atypical lymphocytes with dispersed chromatin, deeply basophilic cytoplasm, and inconspicuous granules were also present. The abnormal lymphocytes were increased in number with disease progression. Additionally, a leukoerythroblastic reaction was observed in all three patients with left shifted neutrophils and occasional nucleated red blood cells.

The bone marrow aspirate smears were available from patients 1 and 2, and showed scattered and loose clusters of abnormal lymphocytes ranging from normal size to large and highly pleomorphic forms; occasional cells close in size to a megakaryocyte were seen. These abnormal lymphocytes showed large nuclei, abundant pale blue cytoplasm, and prominent azurophilic granules (Figure 1).

The bone marrow core biopsies from patients 1 and 2 , and the vertebral bone obtained at autopsy from patient 3 were reviewed and showed abnormal lymphoid infiltrate in a background of hypercellular (85-90\% cellular) bone marrow in all three patients. The abnormal lymphocytes demonstrated predominantly interstitial infiltration with focal subtle sinusoidal infiltration and involved $15-20 \%$ and
$10 \%$ of the bone marrow in patients 1 and 2 , respectively (Figure 2). The neoplastic lymphocytes varied in size ranging from intermediate to large cells with prominent nucleoli, some resembling ReedSternberg cells. Occasional abnormal lymphocytes were present in the sinusoids (Figure 2). Patient 3 showed more profound bone marrow involvement $(50-60 \%)$ with sheets of abnormal lymphocytes. The neoplastic cells were relatively monotonous, medium to large in size (Figure 3); the large, ReedSternberg like cells seen in patients 1 and 2 were not present.

A liver core biopsy was performed in patient 2 and demonstrated abnormal, dense lymphoid infiltrate in the portal area composed of medium to large, highly pleomorphic cells similar to those seen in the bone marrow biopsy. A post-mortem examination of patient 3 showed markedly enlarged liver and spleen. The abnormal lymphoid infiltrate predominantly involved the portal areas in the liver with relatively mild sinusoidal infiltration (Figure 4). The spleen was nearly completely replaced by the abnormal lymphoid infiltrate; large areas of necrosis were also present (Figure 5). Additionally, the abnormal lymphoid infiltrate also involved lymph nodes, kidney, and adrenal glands with no or minimal involvement in other organs. The morphologic findings of the three cases are summarized in Table 2.

\section{Flow Cytometric Immunophenotyping, Immuno- histochemistry, and Molecular Analysis for T-Cell Receptor Gene Rearrangement}

Flow cytometric analysis was performed on the bone marrow aspirate from patients 1 and peripheral blood from patient 2. A distinct NK-cell population with atypical immunophenotype was identified in the initial bone marrow biopsy from patient $1(46 \%$ of the lymphocytes and $10 \%$ of the total cells) and in a peripheral blood sample obtained during disease progression from patient 2 (80\% of lymphocytes and $30 \%$ of total cellular events). In both cases, the NK cells were surface CD3 -, CD2+, CD56+, CD57-, CD4-, CD8 -, CD5 -, TIA1+, granzyme B+, and perforin+, and negative for surface TCR $\alpha \beta$ and $\gamma \delta$. The vast majority of NK cells in these two cases showed atypical phenotype including negative staining for CD7 (2 of 2) and lack of expression of killercell inhibitory receptor (KIR) CD158a/b/e (2 of 2) (Figure 6). The surface CD3+ $\mathrm{T}$ cells showed a slightly inverted CD4 to CD8 cell ratio and were otherwise immunophenotypically unremarkable. The immunophenotype of case 3 (autopsy) was evaluated by immunohistochemistry on the bone marrow, liver, and spleen, and showed that the neoplastic cells were CD3+, CD5-, CD7-, CD4-, CD8 - , CD43+, CD56+, TIA1+, and negative for TCR $\alpha \beta$ and $\gamma \delta$ (Figures 3-5).

The neoplastic NK cells in the bone marrow core biopsy were best visualized by immunohistochemistry. 

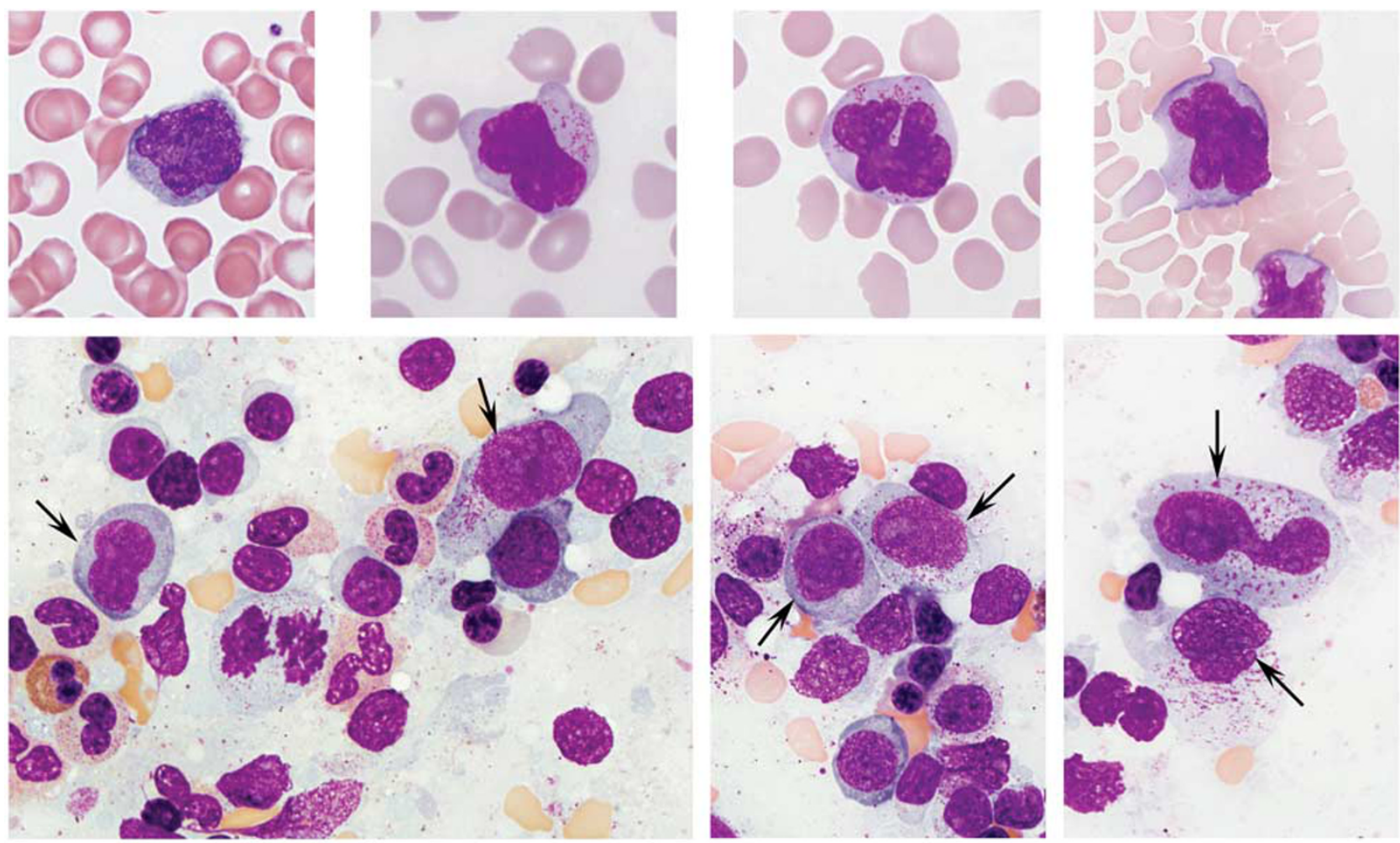

Figure 1 Upper panel: Peripheral blood smears from patients 1 and 2. There is no lymphocytosis but abnormal lymphocytes ranging from medium to large with irregular nuclei, dense chromatin, and pale blue cytoplasm containing azurophilic granules are present, morphologically consistent with abnormal large granular lymphocytes. Occasional atypical lymphocytes demonstrate dispersed chromatin, deeply basophilic cytoplasm, and inconspicuous granules. Bottom panel: The bone marrow aspirate smears from patients 1 and 2. The smears shows increased lymphocytes ranging from small to large and highly pleomorphic cells with large and irregular nuclei, abundant pale blue cytoplasm containing azurophilic granules (arrows).

Immunohistochemical stains for CD56 and TIA1 readily highlighted the abnormal lymphoid infiltrate in the bone marrow in all three patients; however, CD3 staining was variable with weak cytoplasmic staining in the medium to large cells in patient 1 , negative staining in patient 2, and strong cytoplasmic staining in patient 3 (Figures 2 and 3). CD30 marked the large, pleomorphic cells present in patients 1 and 2 (Figure 2). Similar to the flow cytometric immunophenotyping, the abnormal NK cells were negative for all other T-cell (CD4, CD8, CD5, CD7) and B-cell-associated antigens (PAX5, CD20) examined, as well as negative for T-cell receptor $\alpha \beta$ and $\gamma \delta$ by immunohistochemistry. Immunostains for CD163 and/or CD68 were performed on the bone marrow biopsies to rule out a monocytic neoplasm and were negative (patients 1 and 2). In situ hybridization for EBER was performed on the bone marrow biopsy from patient 1, bone marrow and liver biopsies from patient 2, and liver and spleen tissues from patient 3 , and were all negative (Figures 2 and 4). RNA control in all three cases showed adequate preservation of RNA including the decalcified specimens (patients 1 and 2). The results of immunophenotype assessed by flow cytometry and immunohistochemistry are summarized in Table 2 .

Molecular analyses for T-cell receptor gene rearrangement were performed on the bone marrow aspirate (patients 1 and 2) and spleen tissue (patient 3) and did not identify a clonal T-cell receptor gene rearrangement in all three patients. Cytogenetic analysis was performed on the bone marrow aspirate from patients 1 and 2, and revealed a complex karyotype in patient 1 and a normal karyotype in patient 2. The former showed two related complex clones likely representing clonal evolution, including multiple numerical and structural abnormalities and several marker chromosomes (Table 2).

\section{Expression of EZH2, H3K27me3 and MYC, and FISH Analysis for $c$-MYC Gene}

Since activation of PRC2 pathway has been implicated in the pathogenesis of T- and NK-cell lymphomas, particularly EBV-positive tumors, ${ }^{10,12,14}$ we examined the key component of PRC2 pathway EZH2 and its effector H3K27me3 by immunohistochemistry. EZH2 expression and the staining pattern in normal lymphoid tissue has been reported previously. ${ }^{15}$ In all three cases of the study, the neoplastic NK cells showed strong nuclear expression of EZH2 and H3K27me3 (Figure 7). To explore the potential utility of the currently available immunotherapy, PD-L1 inhibitor, for this highly 

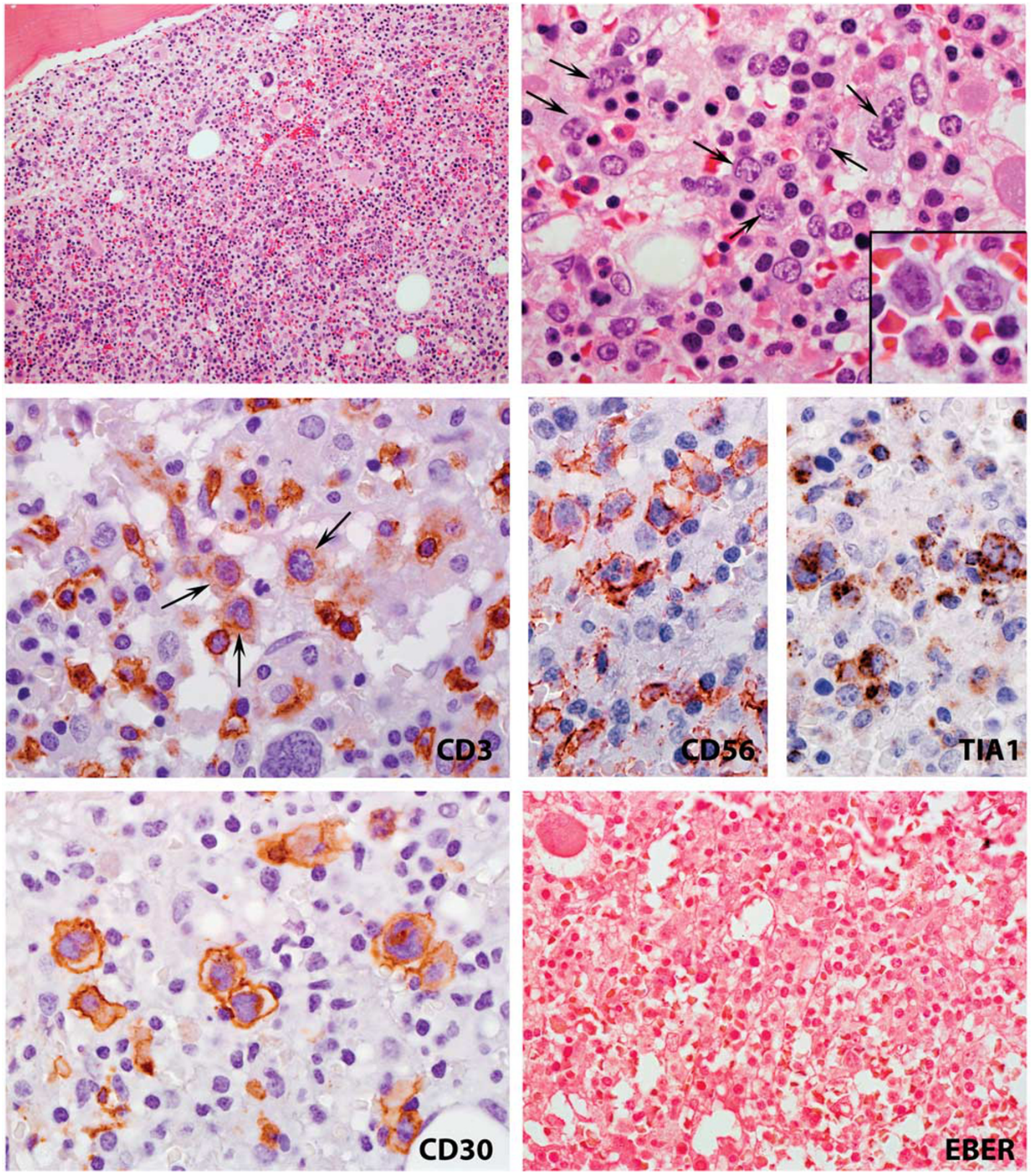

Figure 2 Bone marrow biopsy from patient 1. Top panel: The bone marrow is hypercellular and shows interstitial infiltration of intermediate to large atypical lymphocytes with irregular nuclear outline and distinct to prominent nucleoli. Middle panel: The medium to large neoplastic cells show weak cytoplasmic CD3 staining (arrows), and are positive for CD56 and TIA1. Bottom panel: CD30 is positive in the large cells; in situ hybridization for EBER is negative.

aggressive disease, immunohistochemistry for PD-L1 was performed and showed strong PD-L1 expression in the neoplastic cells in two of three patients (patients 1 and 2) (Figure 7).

Immunohistochemical stain for c-MYC was performed and showed overexpression of c-MYC in the neoplastic cells in all three patients (Figure 5). FISH analysis on the paraffin-embedded spleen tissue from patient 3 using break-apart probes revealed no evidence of $c-M Y C$ gene rearrangement. However, 113 of 200 cells (56.5\%) had 5 to 10 copies of $c-M Y C$ signals consistent with amplification of $C-M Y C$, and 

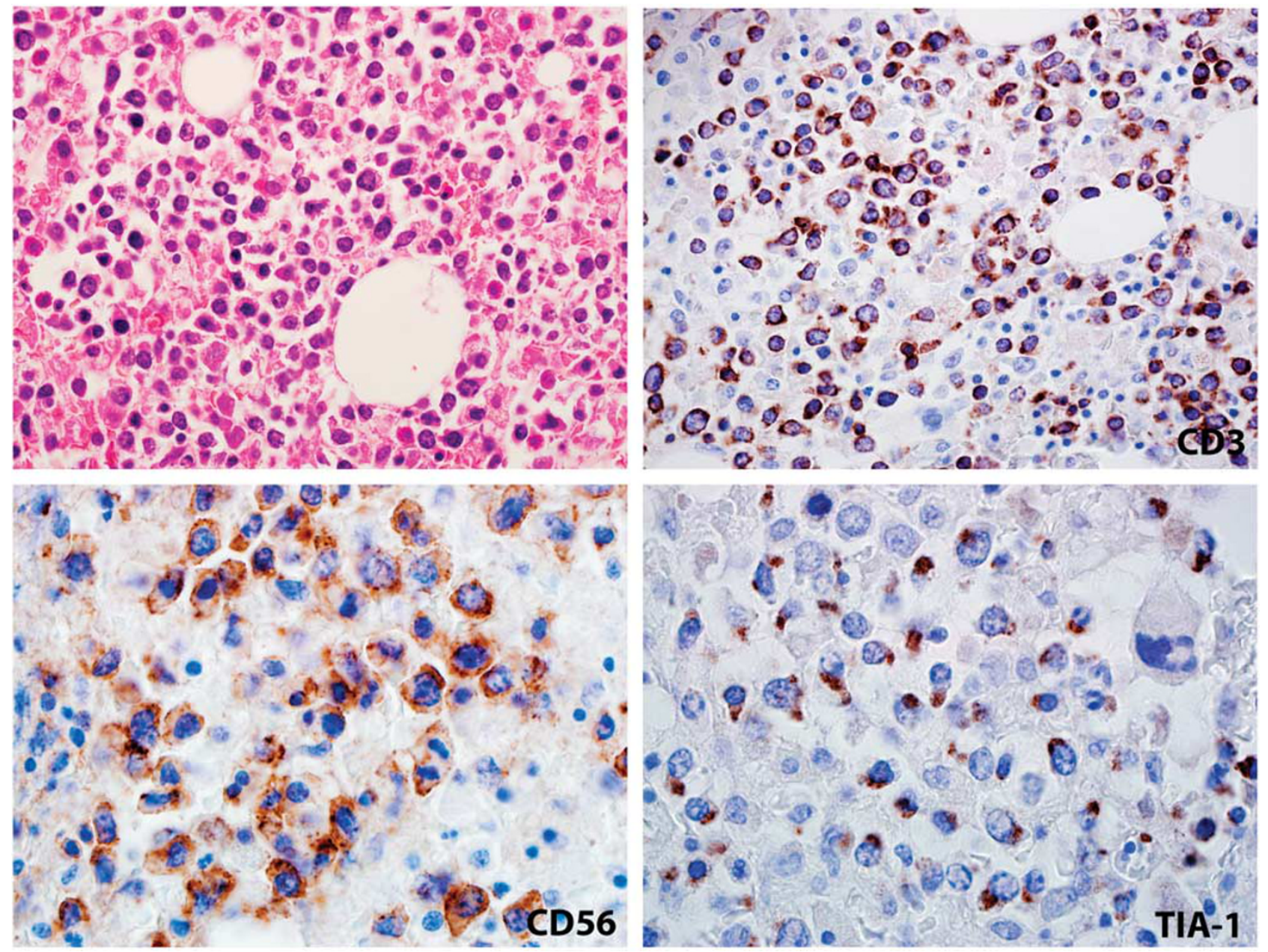

Figure 3 Bone marrow from patient 3 (autopsy). The bone marrow shows extensive involvement by the abnormal lymphoid infiltrate composed of relatively monotonous, medium-sized lymphocytes. The neoplastic lymphocytes are positive for CD3, CD56, and TIA1.

56 of $200(28 \%)$ cells showed 3-4 copies of $c-M Y C$ (Figure 5). FISH for $c-M Y C$ was attempted on the bone marrow touch imprints from patients 1 and 2, but inadequate cells were available for analysis.

\section{Next-Generation Sequencing}

Next-generation sequencing was successfully performed on bone marrow aspirate of patient 1 and paraffin-embedded splenic tissue from patient 3 . The tumor burden in bone marrow (patient 1) and splenic tissue (patient 3) were estimated at $15-20 \%$ and 70 $80 \%$, respectively. A median depth of read of 462 and 561 was achieved for specimens 1 and 3 respectively. A total of 1744 and 1708 variants were detected for these samples; however, using the bioinformatics pipeline mentioned in the method, 28 and 34 filtered variants were identified for patient 1 and patient 3 , respectively. A complete list of these variants with their variant allele fraction are listed in Supplementary Tables S1 and S3.

A total of 27 missense variants and one splice site substitution were identified in sample 1 using the mutant allele frequency threshold of $>10 \%$. All but one (DDX3X p.L514T, variant allele fraction: $12 \%$ ) demonstrated a variant allele fraction of $\sim 50 \%$, and as the tumor burden was $15-20 \%$ it was thought to represent single-nucleotide polymorphism. To further evaluate the presence of variants with lower allele frequency, a manual curation of variants with allele frequency between 5 and $10 \%$ was done and successfully identified eight more variants including IDH2 p.R140Q mutation (variant allele fraction: $5 \%$ ), two TET2 mutations (p.P1894L, variant allele fraction: 5\%, p.Q1903X, variant allele fraction: $5 \%$ ), and a TP53 p.V197M mutation (variant allele fraction: 9\%).

Splenic tissue from patient 3 demonstrated 34 alterations, including one frameshift deletion (SRSF3 p.F50fs* 4 , variant allele fraction: $26 \%$ ), one in frame deletion (STX11 p.L9del), three non-sense mutations (FOXP1 p.Gln173*, variant allele fraction: $26 \%$; HIST1H3J p.Gln69*, variant allele fraction: $16 \%$; TP53 p.Leu35*, variant allele fraction: $21 \%$ ), 22 exonic missense variants, and 7 splice site variant. The missense variants included a PMS2 p.R563L (variant allele fraction: $55 \%$ ) and an ATM p.D1853V 

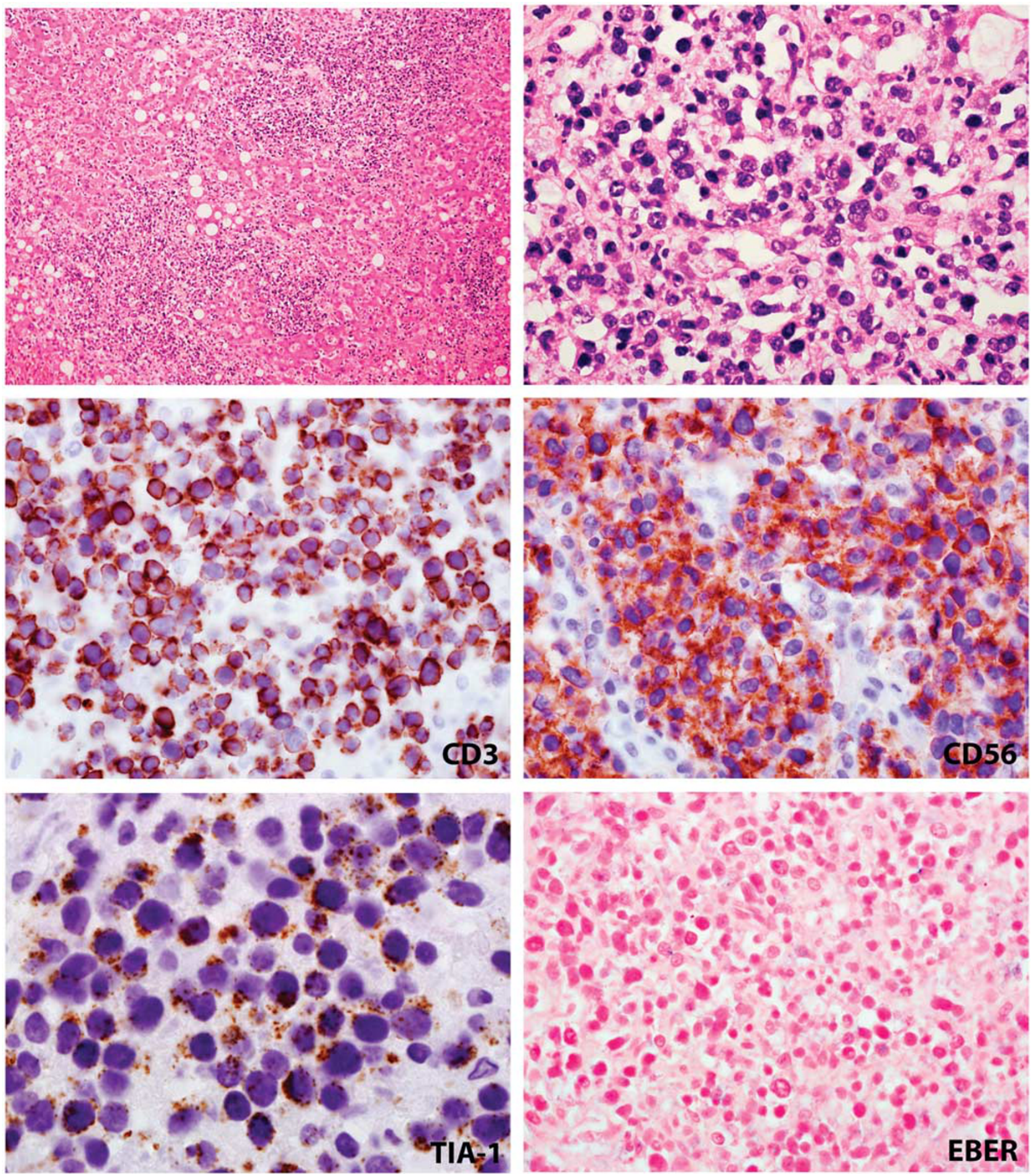

Figure 4 Liver tissue from patient 3 (autopsy). Top panel: The neoplastic cells show predominantly portal infiltration. Middle and bottom panels: The neoplastic cells are positive for CD3, CD56, TIA1 and negative for EBER.

(variant allele fraction: 64\%) variants. The presence of PMS2 variant raised the possibility of microsatellite instability, thus immunohistochemical stains for MLH1, PMS2, MSH2, and MSH6 were performed on the splenic tissue of patient 3 and showed no loss of expression for all four mismatch repair proteins in the lymphoma cells.
Copy number changes were only tested in the autosomal chromosomes for regions covered by the assay. Bone marrow specimen (patient 1) showed no copy number changes seen across this panel. Splenic tissue from patient 3 showed amplification of the partial chr6p (including WHSC1L1) and chr8q (including NBN, RAD21, CSMD3, FGFR1, and MYC). 

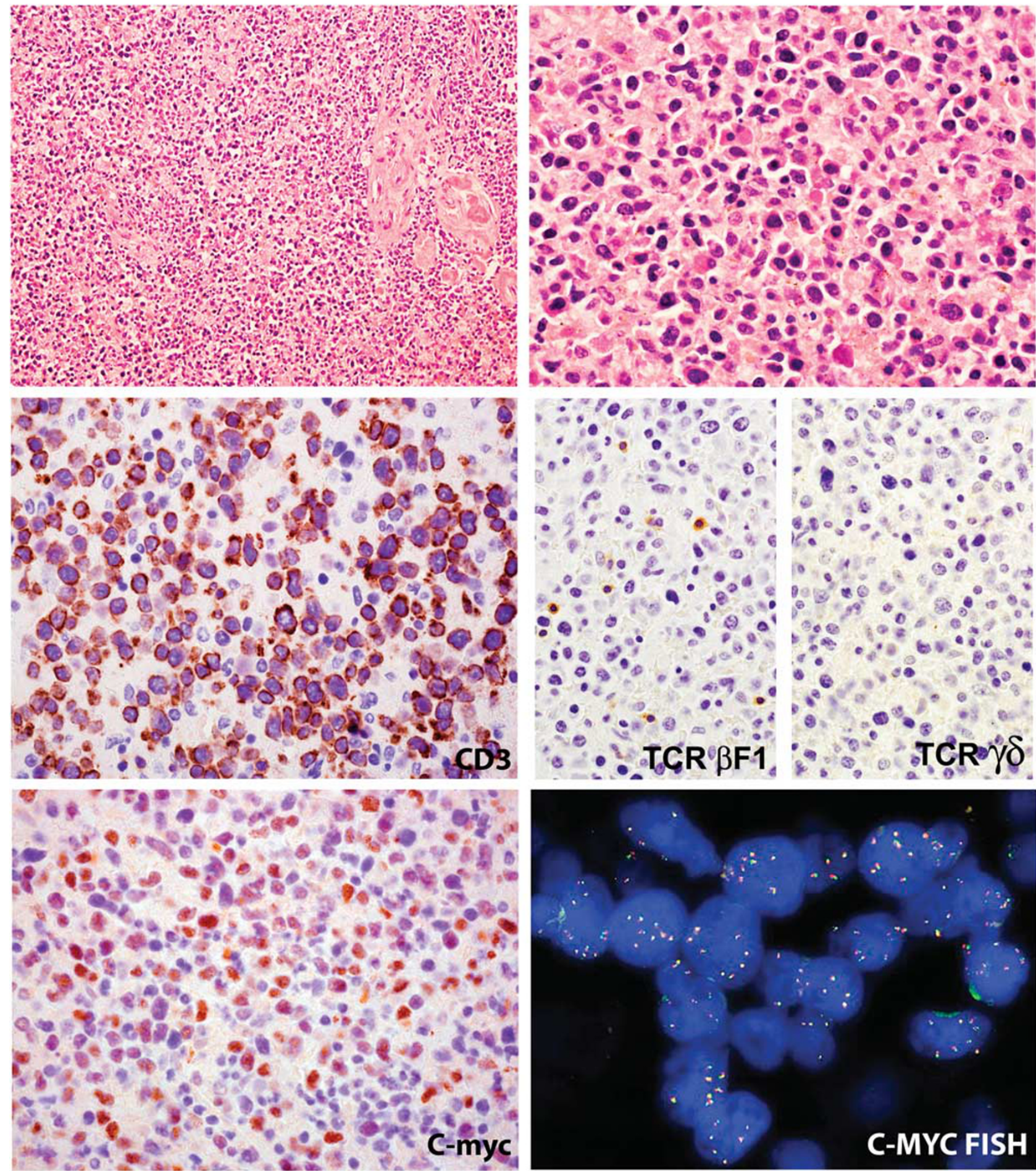

Figure 5 Spleen tissue from patient 3 (autopsy). Top panel: The neoplastic cells extensively involve the red and white pulp. Middle panel: The neoplastic cells are positive for CD3 and negative for $\beta F 1$ and TCR $\gamma \delta$. Bottom panel: The neoplastic NK cells show overexpression of C-MYC in 40-50\% cells. FISH analysis using break-apart probe demonstrates $>5$ copies of intact $c$ - $M Y C$ signals in each cell, indicating an amplification of $c-M Y C$ gene; no $c-M Y C$ gene rearrangement is identified.

\section{Discussion}

Current WHO classification of hematopoietic neoplasms (2008) recognizes three types of NK-cell neoplasm: extranodal NK/T-cell lymphoma nasal type, aggressive NK-cell leukemia/lymphoma, and chronic lymphoproliferative disorder of NK cells. The first two NK-cell neoplasms are aggressive and strongly associated with EBV infection. Aggressive NK-cell leukemia/lymphoma is a rare form of leukemia/lymphoma that preferentially affects Asians, ${ }^{16}$ and commonly involves peripheral blood, 
Table 2 Pathologic features of EBV-negative aggressive NK-cell leukemia/lymphoma

\begin{tabular}{|c|c|c|c|}
\hline & Patient 1 & Patient 2 & Patient 3 \\
\hline Peripheral blood & $\begin{array}{l}\text { No lymphocytosis but large highly } \\
\text { atypical granular lymphocytes } \\
\text { present; left shift of neutrophils }\end{array}$ & $\begin{array}{l}\text { No lymphocytosis but large highly } \\
\text { atypical granular lymphocytes } \\
\text { present; left shift of neutrophils }\end{array}$ & $\begin{array}{l}\text { No lymphocytosis with very } \\
\text { rare atypical granular } \\
\text { lymphocytes; left shift of } \\
\text { neutrophils }\end{array}$ \\
\hline \multicolumn{4}{|l|}{ Bone marrow } \\
\hline Cellularity & Hypercellular (85\%) & Hypercellular (90\%) & Hypercellular (90\%) \\
\hline Extent of involvement & $15-20 \%$ & $10 \%$ & $50-60 \%$ \\
\hline Liver & NA & $\begin{array}{l}\text { Dense portal infiltration with milder } \\
\text { intrasinusoidal infiltration }\end{array}$ & $\begin{array}{l}\text { Dense portal infiltration with } \\
\text { milder intrasinusoidal } \\
\text { infiltration; necrosis }\end{array}$ \\
\hline Spleen & NA & NA & $\begin{array}{l}\text { Extensive infiltration with } \\
\text { virtually complete replacement } \\
\text { of both white and red pulp; } \\
\text { necrosis }\end{array}$ \\
\hline Other organs involved & NA & NA & $\begin{array}{l}\text { Involvement of lymph nodes, } \\
\text { kidney, and adrenal glands; } \\
\text { minimal or no involvement in } \\
\text { other organs }\end{array}$ \\
\hline $\begin{array}{l}\text { Immunophenotype } \\
\text { (FC \& IHC) }\end{array}$ & $\begin{array}{l}\text { FC and IHC: CD45+, sCD3 - , cCD3+, } \\
\text { CD2+, CD5 -, CD7 -, CD4-, CD8 -, } \\
\text { CD16+, CD56+, CD57-, TIA1+, } \\
\text { granzyme B+, perforin+, CD158 (a/b/ } \\
\text { e) -, TCR } \alpha \beta-, \text { and TCR } \gamma \delta-\end{array}$ & $\begin{array}{l}\text { FC and IHC: CD45+, sCD3-, } \\
\text { cCD3 - , CD2+, CD5-, CD7-, } \\
\text { CD4-, CD8 -, CD16-, CD56+, } \\
\text { CD57-, TIA1+, granzyme B+, } \\
\text { perforin+, CD158 (a/b/e) - , TCR } \\
\alpha \beta-\text { and TCR } \gamma \delta-.\end{array}$ & $\begin{array}{l}\text { IHC only: CD3+, CD5 -, CD7 -, } \\
\text { CD4 - , CD8 - , CD } 43+, \text { CD56+, } \\
\text { TIA1+, } \beta \text { F1 - , TCR } \gamma-\end{array}$ \\
\hline EBER & Negative & Negative & Negative \\
\hline $\begin{array}{l}\text { Clonal TCR gene } \\
\text { rearrangement }\end{array}$ & Negative & Negative & Negative \\
\hline PRC proteins and other & EZH2+, H3K23Me3+ & EZH2+, H3K27Me3+ & EZH2+, H3K27Me3+ \\
\hline biomarkers (IHC) & CD30+, PD-L1+ & CD30+, PD-L1+ & CD30 - , PD-L1 - \\
\hline c-MYC overexpression & Yes & Yes & Yes \\
\hline$c-M Y C$ rearrangement & NA (inadequate cells) & NA (inadequate cells) & Negative \\
\hline$c-M Y C$ amplification & NA (inadequate cells) & NA (inadequate cells) & $\begin{array}{l}\text { Yes ( } \geq 5 \text { copies of } c-M Y C \\
\text { signals in } 56.5 \% \text { of neoplastic } \\
\text { cells) }\end{array}$ \\
\hline Cytogenetics & $\begin{array}{l}\text { Clone 1: } \\
47 \sim 60, X Y,+X,+Y,+1, \operatorname{ider}(1)(q 10) \\
\text { add(1)(q32),+3,+4,+6,+7, }-9,+10, \\
+11,+13, \text { add(13)(q34),+14,+14,+18, } \\
+19,+20, \text { add(21)(p11.3),+add(21) } \\
\text { p11.1)x3,+mar1,+mar2+mar3[cp5] } \\
\text { Clone2: } \\
\text { 83, idem,+X,+2,+3,+3,+5,+5,+6,+7, } \\
+8,+9,+9,+10,+1, \operatorname{del}(11)(q 23),+12, \\
\text { +add(13)(q34),+15,+16,+20,+22[3] } \\
\text { Normal: 46,XY[12] }\end{array}$ & 46, XY[20] & NA \\
\hline
\end{tabular}

Abbreviations: FC, flow cytometry; IHC, immunohistochemistry; NA, not available; PRC, polycomb repressive complex.

bone marrow, liver, and spleen although any organs can be affected. The neoplastic cells show a range of morphology from relatively normal-appearing large granular lymphocytes to highly atypical cells with ample cytoplasm and azurophilic granules. The bone marrow may show subtle, focal or diffuse involvement and may associate with hemophagocytosis. ${ }^{1}$ The immunophenotype of aggressive NK-cell leukemia/lymphoma is suggestive of a neoplastic counterpart of a normal NK cell that has undergone activation and transformation after EBV infection. ${ }^{17,18}$ Evidence of EBV infection is a key diagnostic feature of aggressive NK-cell leukemia/lymphoma. EBVnegative aggressive NK-cell leukemia/lymphoma is rare and its clinicopathological features are not well recognized. There are anecdotal case reports in the literature describing neoplastic proliferation of NK cells with aggressive clinical course but no EBV association. ${ }^{2-5,19}$ Two small series on typical EBVpositive aggressive NK-cell leukemia/lymphoma included 2 out of 13 and 2 out of 14 EBV-negative patients. ${ }^{6,7}$ One of the small series reported the absence of EBV had no prognostic significance as both EBV-negative patients died of aggressive disease within 1-2 months. ${ }^{6}$ The other series reported patients with EBV-negative aggressive NK-cell leukemia/lymphoma had a less aggressive clinical course and a longer survival than EBV-positive 

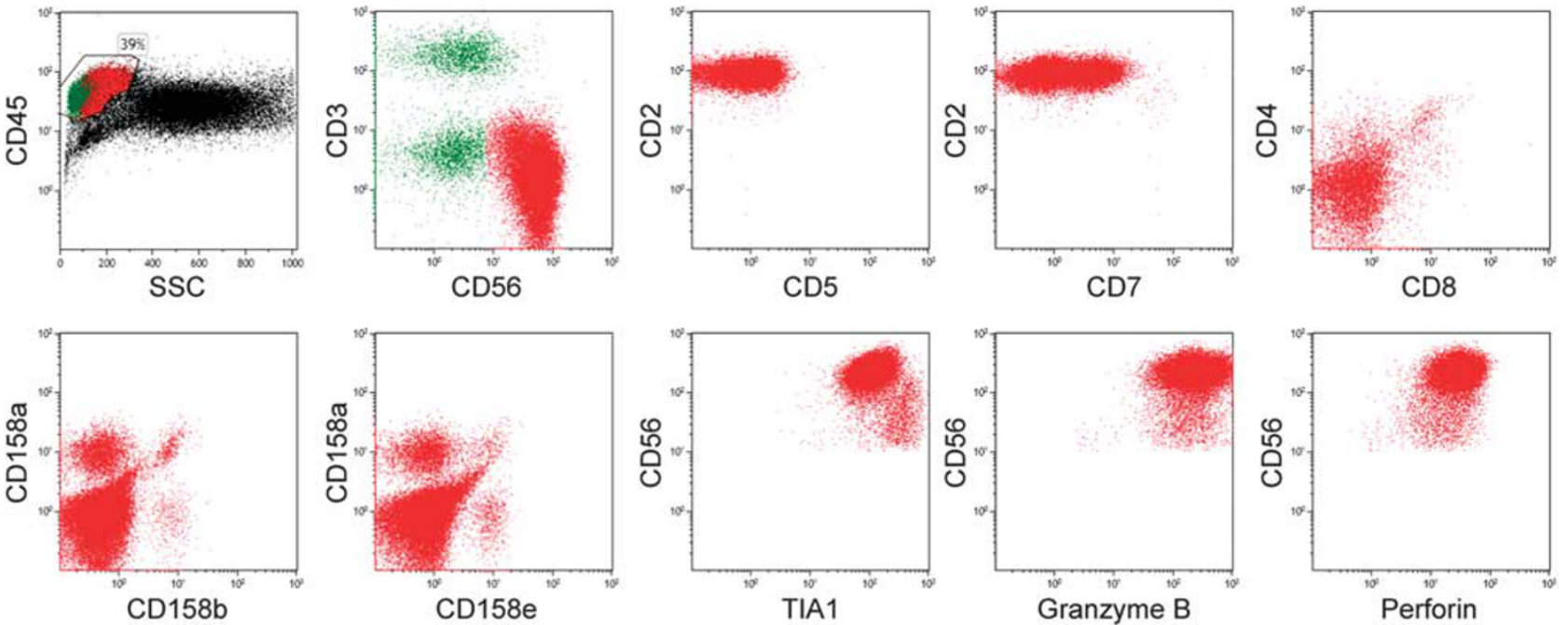

Figure 6 Flow cytometric analysis on a peripheral blood sample from patient 1. Flow cytometric analysis identifies a large abnormal NK (CD3 - CD56+) cell population (red events) that is CD2+, CD5 - , CD7 - , CD4 - , CD8 - , expresses cytotoxic markers TIA1, granzyme B, and perforin. The vast majority of the NK cells are negative for killer-cell inhibitory receptor CD158a/b/e, but a small subset expresses predominantly CD158a. Normal T and B cells (green events) and granulocytes (black events) are also present.

patients (11.5 vs 1.5 months). ${ }^{7}$ Recently, Nicolae et al. published a series of seven patients with EBVnegative aggressive NK-cell leukemia/lymphoma, and six died of the disease including five that died within 8 weeks from the onset of symptoms. The only survivor received allogeneic bone marrow transplant. ${ }^{9}$

In the present study, we evaluated clinicopathological features of three cases of EBV-negative aggressive NK-cell leukemia/lymphoma from our institution, including a case diagnosed on postmortem examination. All three patients were nonAsian (two Caucasians, one African-American) and showed typical clinical features of aggressive NK-cell leukemia/lymphoma, including systemic symptoms, involvement of peripheral blood, bone marrow, liver and spleen, and fulminant clinical disease course. Two of the three patients (patients 1 and 3) died within the first week of admission and 2-3 weeks of onset of symptoms, and Patient 2 died in 3 months despite receiving chemotherapy. The diagnosis of EBV-negative aggressive NK-cell leukemia/lymphoma was made on the bone marrow biopsy in patient 1 , bone marrow and liver biopsies in patient 2 , and postmortem examination in patient 3. Although some of the previous reports hinted at a more indolent clinical course of patients with EBV-negative aggressive NKcell leukemia/lymphoma, ${ }^{2,5,7,19}$ our findings indicate that the EBV-negative aggressive NK-cell leukemia/ lymphoma is highly aggressive and shares similar clinical features to EBV-positive counterpart, which is in agreement with the findings of the most recent study by Nicolae et al. ${ }^{9}$ Interestingly, the Asian predilection of EBV-positive aggressive NK-cell leukemia/lymphoma is not observed in this small series of EBV-negative cases (2 Caucasians, one African-
American), which is also in agreement with the report by Nicolae et al (five white, one black, and one Asian). ${ }^{9}$

An early diagnosis of EBV-negative aggressive NK-cell leukemia/lymphoma is difficult. The acute presentation of fevers and splenomegaly and occasional atypical lymphocytes in the blood smear may subject the patient to an extensive infectious workup, as was the case in two of our three patients. When a bone marrow biopsy is performed, the abnormal NK-cell infiltrate could be overlooked due to interstitial infiltration in a background of a hypercellular bone marrow. To make the initial recognition of the disease in the bone marrow even more challenging is the negative immunostaining for CD3 in some cases, as seen in patient 2 in this series, as well as negative staining for EBER. The NK-cell nature of the abnormal lymphocytes was confirmed in this study by flow cytometric analysis, a battery of immunohistochemical stains and the absence of a clonal $\mathrm{T}$-cell receptor gene rearrangement by molecular analysis. Additionally, aggressive NK-cell leukemia/lymphoma is associated with a high incidence of hemophagocytic lymphohistiocytosis, which occurred in one of our patients (patient 2) at initial presentation. The interstitial atypical lymphocytes in the bone marrow could be masked or interpreted as secondary to hemophagocytic lymphohistiocytosis. Patient 3 in this study had a history of chronic myelogenous leukemia and presented with marked hepatosplenomegaly thought to be chronic myelogenous leukemia progression, and the patient died 3 days after admission before obtaining any tissue biopsy. The post-mortem examination showed extensive abnormal lymphoid infiltration in the bone marrow, liver, spleen, and lymph 
Bone Marrow (Patient 1)
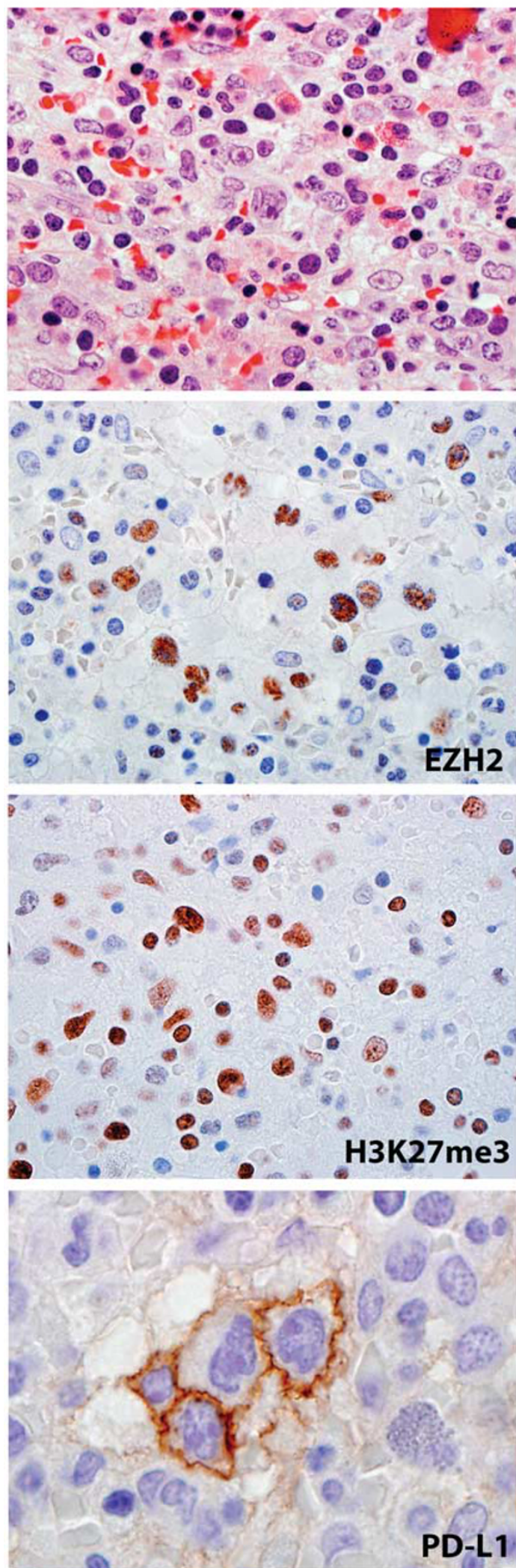

Liver (Patient 3)

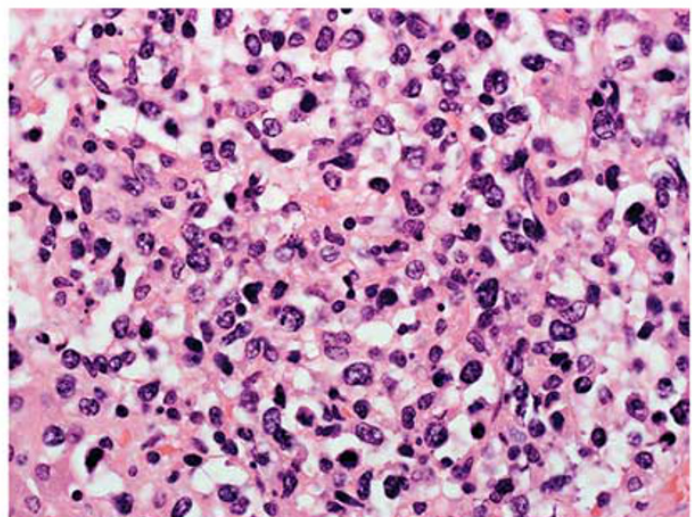

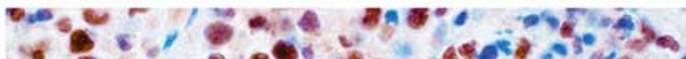

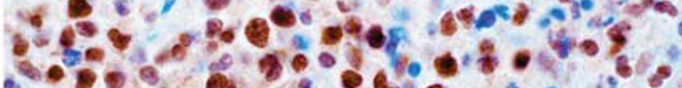

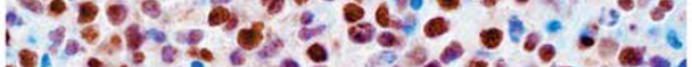

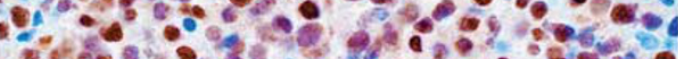

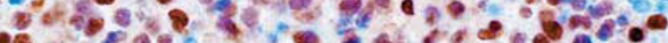

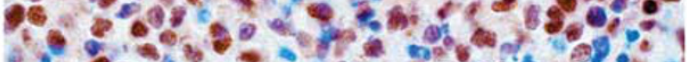
$0.22^{\circ}$. nos.

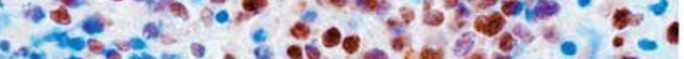

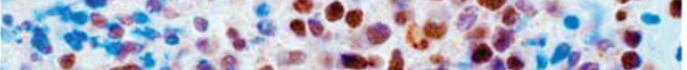
$\therefore$ a

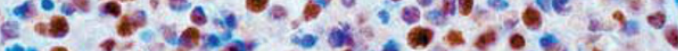

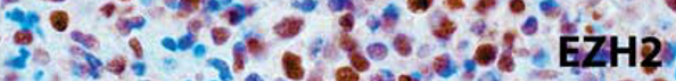

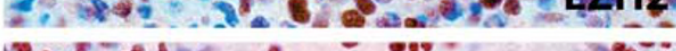

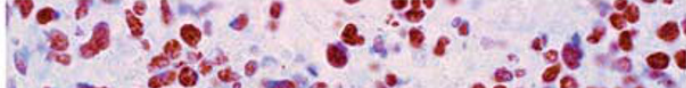

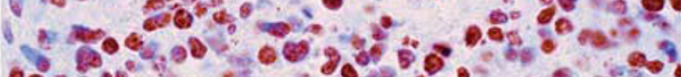

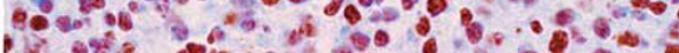

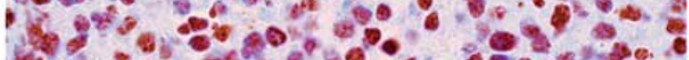

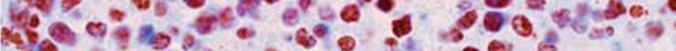

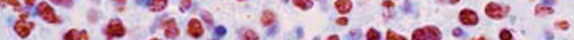
* 000.0

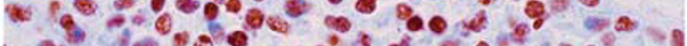

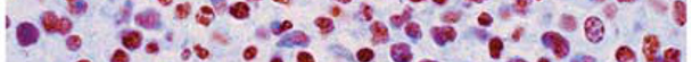

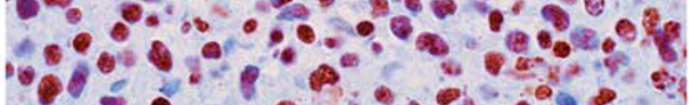

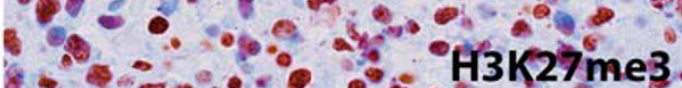

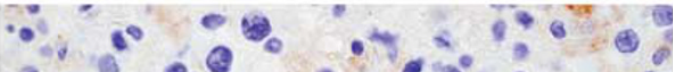

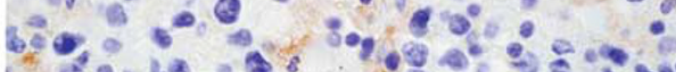

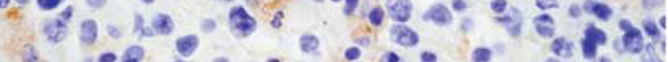

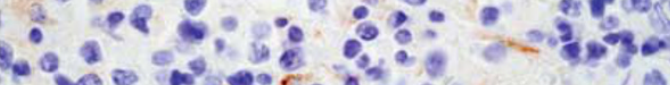
$100=0^{\circ} 0^{2} \log$ is

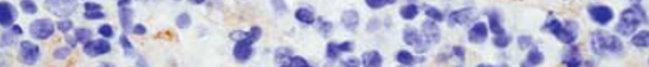

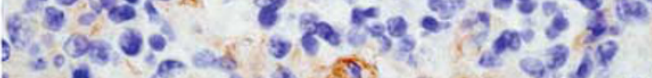

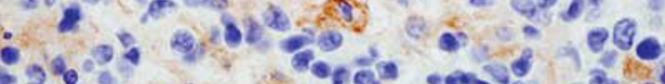
96 -

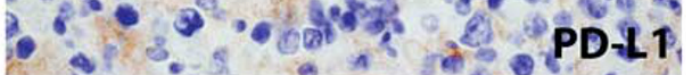

Figure 7 Expression of EZH2, H3K27me3, and PD-L1 in neoplastic NK cells in patient 1 and patient 3. Middle two panels: Overexpression of EZH2 and H3K27me3 are seen in the neoplastic NK cells in the bone marrow biopsy from patient 1 and liver tissue from patient 3. Bottom panel: PD-L1 is positive in the neoplastic cells in patient 1, but negative in patient 3 . The admixed histiocytes are positive in patient 3. Immunostaining on the bone marrow biopsy from patient 2 is positive for EZH2, H3K27me3, and PD-L1 (not shown). 
node. The initial immunohistochemical stains (CD3+, CD5 - , CD4-, CD8-, CD56+, CD57-, TIA1+, $\beta \mathrm{F} 1-$, EBER -) suggested the possibility of a hepatosplenic T-cell lymphoma; however, the infiltrative pattern in the bone marrow (interstitial without apparent intrasinusoidal) and spleen (extensive involvement of both white and red pulp) and lymph node involvement are not typical for hepatosplenic T-cell lymphoma. Additional studies done retrospectively on this case confirmed the NK-cell nature of the neoplastic cells, including negative staining for TCR $\alpha \beta$ and $\gamma \delta$, and absence of a clonal T-cell receptor gene rearrangement by PCR.

The results of our study indicate that EBER negativity or even CD3 negativity by immunohistochemistry does not rule out the possibility of an aggressive NK-cell neoplasm. In our three cases, CD56 and TIA1 were the consistent positive markers that readily highlighted the neoplastic infiltrate in the bone marrow. In fact, the positive staining for CD56 in the highly pleomorphic cells in the bone marrow biopsy from patient 2 was the first clue leading to the further work-up for an NK-cell neoplasm since the neoplastic cells were negative for CD3 and other T-cell antigens (CD5, CD7, CD4, CD8) in the initial immunohistochemical panel.

Flow cytometric analysis was performed on the bone marrow aspirate in patient 1 and peripheral blood in patients 2, and revealed significantly increased proportion of NK cells within the lymphocyte population in both patients. The NK cells demonstrated aberrant immunophenotype, including negative staining for CD7 (3 of 3) and lack of expression of all three CD158 isoforms in over 90\% of NK cells ( 3 of 3). Thus, flow cytometric analysis, particularly when performed on a blood sample, may serve as an early clue and prompt further work-up to evaluate for the possibility of an NK-cell neoplasm. Careful examination of the blood smears is important. Although lymphocytosis was not present in any of our three patients, abnormal lymphocytes with azurophilic granules were identified in two of three patients at the time of diagnosis.

A variety of cytogenetic abnormalities have been reported in aggressive NK-cell leukemia/lymphoma. A complex karyotype is most common and was reported in eight of nine cases of EBV-positive aggressive NK-cell leukemia/lymphoma. ${ }^{20}$ Suzuki et $a l^{6}$ examined 19 cases of aggressive NK-cell leukemia/lymphoma with cytogenetic findings and reported 10 with abnormal cytogenetic findings, among which 7 were complex karyotype. Cytogenetic analysis was performed on the bone marrow aspirate in two of our patients, and revealed a complex karyotype in one patient. A normal karyotype was seen in another patient who had a relatively low-level bone marrow involvement by NK leukemia/lymphoma.

EBV infection is a well-known factor in T- and NK-cell tumorgenesis although the exact mechanism is still unknown. Most of these tumors demonstrate a cytotoxic phenotype, suggesting that they probably arise from cells activated or transformed during EBV infection. The malignant transformation of NK cells may also be triggered by other etiologic factors independent of EBV infection. Gene expression profiling performed on the extranodal nasal-type NK/T-cell lymphoma showed deregulation of p53 and activation of MYC and NF-kappa B, possibly driven by EBV LMP-1, resulting in the upregulation of survivin. ${ }^{11}$ More recently, the role of PRC2 pathway has been implicated in the pathogenesis of T- and NK-cell lymphomas. ${ }^{10,12,14}$ PRC2 is a multiprotein complex composed of several core components including EZH2, a histone methyltransferase responsible for epigenetic silencing of target genes via trimethylation of H3K27. Increased or unchecked PRC2 activity hypermethylates H3K27 and leads to the repressing of tumor suppressor genes. EZH2 is one of the genes that is differentially overexpressed in extranodal nasal-type NK/T-cell lymphoma identified by genome-wide expression profiling. ${ }^{11}$ Knock-down of EZH2 by a PRC2 inhibitor in nasal NK/T-cell lymphoma cell lines results in cell growth inhibition, indicating that EZH2 overexpression confers growth advantage in the neoplastic NK/T cells. ${ }^{12}$ Kim et al. ${ }^{10}$ studied the activation of PRC2 and expression of H3K27me3 by immunohistochemistry in 175 cases of various types of T- and NK-cell lymphomas and found overexpression of EZH2 and H3K $27 \mathrm{me} 3$ in $54.7 \%$ and $40.5 \%$ patients, respectively. These studies provide strong evidence that activation of PRC2 pathway plays an important role in the pathogenesis of NK/T-cell neoplasms. Although previous studies have identified EBV infection as an epigenetic driver that results in the aberrant methylation of PRC-target genes, ${ }^{21,22}$ it is possible that factors other than EBV may also function in a similar manner. The association between MYC and PRC2 pathway has been reported in various cancer types including hematologic malignancy. ${ }^{23-26}$ MYC interacts with PRC2 through EZH2 and other cofactors such as SUZ12/EED, and is responsible for inducing histone modification of H3K27me3. ${ }^{23,27,28} \mathrm{Kim}$ et $a l^{10}$ also studied the relationships of PRC proteins with MYC, EBV infection, and CD30 in NK/T-cell lymphomas, and reported that MYC expression was highly associated with co-activation of PRC2 proteins, and MYC expression but not EBV infection was positively correlated with CD30 expression.

In this study, we evaluated the key component of PRC2 pathway EZH2 and its effector H3K27 and showed overexpression of EZH2 and trimethylated H3K27 in all three cases of EBV-negative aggressive NK-cell leukemia/lymphoma, suggesting the activation of PRC2 pathway. Additionally, the possible activator of PRC2 pathway c-MYC and CD30 were also examined, and showed overexpression of c-MYC in the neoplastic NK cells in all three cases and CD30 expression in two of three cases. The findings are similar to what have been reported in other types of 
EBV-positive NK/T-cell lymphomas. ${ }^{10-12}$ We further performed FISH analysis for $c-M Y C$ gene and showed amplification ( $\geq 5$ copies) in $56.5 \%$ of neoplastic NK cells in spleen tissue from patient 3 ; no $c-M Y C$ rearrangement was identified. It is reasonable to assume that the overexpression of MYC in patient 3 is likely secondary to the $c-M Y C$ amplification. Unfortunately, FISH was unsuccessful in patients 1 and 2 due to inadequate cells present in the bone marrow touch imprints. Although our case series is small, the results provide evidence that the PRC2 pathway is likely activated and may be associated with overexpression of $\mathrm{c}-\mathrm{MYC}$ in EBV-negative aggressive NK-cell leukemia/lymphoma, similar to previously reported in other types of EBV-positive NK/T-cell lymphomas. ${ }^{10}$ However, further studies on a larger number of patients with aggressive NK-cell leukemia/lymphoma are needed to confirm the findings. Understanding the role of dysregulated PRC2 pathway and its triggering factors in aggressive NK-cell leukemia/lymphoma is important and may have therapeutic implication for targeted therapy as aggressive NK-cell leukemia/lymphoma are refractory to chemotherapy. Additionally, we found strong expression of PD-L1 and CD30 in two of the three patients, suggesting potential application of PD-1 inhibitor or anti-CD30 antibodies as therapeutic options for aggressive NK-cell leukemia/lymphoma.

Prior studies investigating mutational landscape of EBV-associated extranodal NK/T-cell lymphomas have reported recurrent mutations in genes involved in JAK-STAT pathway(STAT3, JAK3) and chromatin modification (MLL2, BCOR) as well as tumor suppressor genes (TP53, FAS). ${ }^{29-32}$ Among these, the mutations leading to activation of the JAK-STAT pathway are shown to play a significant role in pathogenesis of these neoplasms. ${ }^{29,33}$ Genetic alteration in EBV-negative NK/T-cell lymphoma is unclear. A recent study performed limited sequencing on two of these lymphomas and found point mutations of STAT3 gene on both cases. ${ }^{9}$ In the present study, we successfully performed nextgeneration sequencing on two of three cases using a comprehensive panel that included full exon sequencing of 1212 genes; however, no mutation in genes associated with JAK-STAT pathway was identified. The results suggest that alternative molecular mechanisms may be involved in the pathogenesis of EBV-negative aggressive NK-cell leukemia/ lymphoma. One of our cases demonstrated several somatic alterations, including frameshift mutation in SRSF3, stop gain mutations in TP53, FOXP1, HIST1H3J, and a novel hemi-zygote mutation in ATM gene. The other case (case 1) also included a TP53 mutation as well as hot-spot mutation of IDH2 gene and two mutations of TET2 gene. Notably, as the specimen for the latter case was a bone marrow aspirate with 15-20\% involvement by lymphoma, we could not confirm if these mutations were from the lymphoid cells rather than myeloid elements although there was no morphologic evidence of a myeloid neoplasm.

In summary, the results of our study indicate that the EBV-negative aggressive NK-cell leukemia/lymphoma share similar clinical and morphologic features to EBV-positive NK-cell leukemia/lymphoma except for the high prevalence of Asians seen in EBV-positive cases. Awareness of this rare EBV-negative variant of aggressive NK-cell leuke$\mathrm{mia} /$ lymphoma is important in early diagnosis of this highly aggressive disease. The evidence of activation PRC2 pathway and expression of PD-L1 and CD30 in the neoplastic NK-cell suggest potential therapeutic targets for this disease. Next-generation sequencing did not identify JAK-STAT pathway-associated gene mutations previously reported in EBV-positive NK/T-cell lymphoma, suggesting alternative molecular pathogenic mechanisms for EBV-negative aggressive NK-cell leukemia/lymphoma.

\section{Acknowledgments}

We thank Drs Yanming Zhang and Xinyan Lu and Ms Jeanne Olstad in the Cytogenetics Laboratory at Northwestern Memorial Hospital (NMH) for performing FISH analysis for C-MYC, Dr Qing Chen and Ms Jessica Binder in the Immunohistochemistry Laboratory at NMH for helping with immunohistochemical studies, and Drs Sabah Kadri, Ibro Mujacic, Michelle N Wurst, and Jeremy $\mathrm{P}$ Segal in the Division of Genomic and Molecular Pathology at University of Chicago for performing next-generation sequencing and data analysis.

\section{Disclosure/conflict of interest}

The authors declare no conflict of interest.

\section{References}

1 Chan JK, Jaffe ES, Ralfkiaer E, et al. Aggressive NK-cell leukaemia. In: Swerdlow SH, Campo E, Harris NL, et al. (eds). WHO Classification of Tumours of Haematopoietic and Lymphoid Tissues, 4th edn. WHO Publications Center: Lyon, 2008, pp 276-277.

2 Jitani AK, Khonglah Y, Kumar R, et al. Natural killer cell lymphoma: a case with classification dilemma. J Clin Diagn Res 2016;10:ED07-ED08.

3 Matano S, Nakamura S, Nakamura S, et al. Monomorphic agranular natural killer cell lymphoma/leukemia with no Epstein-Barr virus association. Acta Haematol 1999;101:206-208.

4 Perkovic S, Basic-Kinda S, Gasparovic V, et al. EpsteinBarr virus-negative aggressive natural killer-cell leukaemia with high P-glycoprotein activity and phosphorylated extracellular signal-regulated protein kinases 1 and 2. Hematol Rep 2012;4:e16.

5 Park JA, Jun KR, Nam SH, et al. Favorable outcome in a child with EBV-negative aggressive NK cell leukemia. Int J Hematol 2013;97:673-676. 
6 Suzuki R, Suzumiya J, Nakamura S, et al. Aggressive natural killer-cell leukemia revisited: large granular lymphocyte leukemia of cytotoxic NK cells. Leukemia 2004;18:763-770.

7 Ko YH, Park S, Kim K, et al. Aggressive natural killer cell leukemia: is Epstein-Barr virus negativity an indicator of a favorable prognosis? Acta Haematol 2008;120:199-206.

8 Zhang Q, Jing W, Ouyang J, et al. Six cases of aggressive natural killer-cell leukemia in a Chinese population. Int J Clin Exp Pathol 2014;7:3423-3431.

9 Nicolae A, Ganapathi KA, Pham TH, et al. EBVnegative aggressive NK-cell leukemia/lymphoma: clinical, pathologic, and genetic features. Am J Surg Pathol 2016;41:67-74.

$10 \mathrm{Kim}$ SH, Yang WI, Min YH, et al. The role of the polycomb repressive complex pathway in $\mathrm{T}$ and NK cell lymphoma: biological and prognostic implications. Tumour Biol 2016;37:2037-2047.

$11 \mathrm{Ng}$ SB, Selvarajan V, Huang G, et al. Activated oncogenic pathways and therapeutic targets in extranodal nasal-type NK/T cell lymphoma revealed by gene expression profiling. J Pathol 2011;223:496-510.

12 Yan J, Ng SB, Tay JL, et al. EZH2 overexpression in natural killer/T-cell lymphoma confers growth advantage independently of histone methyltransferase activity. Blood 2013;121:4512-4520.

13 Kadri S, Long BC, Mujacic I, et al. Clinical validation of a next-generation sequencing genomic oncology panel via cross-platform benchmarking against established amplicon sequencing assays. J Mol Diagn 2017;19: 43-56.

14 Nagel S, Venturini L, Marquez VE, et al. Polycomb repressor complex 2 regulates HOXA9 and HOXA10, activating ID2 in NK/T-cell lines. Mol Cancer 2010; 9:151.

15 Zhou Z, Gao J, Popovic R, et al. Strong expression of EZH2 and accumulation of trimethylated $\mathrm{H} 3 \mathrm{~K} 27$ in diffuse large B-cell lymphoma independent of cell of origin and EZH2 codon 641 mutation. Leuk Lymphoma 2015;56:2895-2901.

16 Ruskova A, Thula R, Chan G. Aggressive natural killercell leukemia: report of five cases and review of the literature. Leuk Lymphoma 2004;45:2427-2438.

17 Lima M. Extranodal NK/T cell lymphoma and aggressive NK cell leukaemia: evidence for their origin on CD56+bright CD16-/+dim NK cells. Pathology 2015;47: 503-514.

18 Lima M, Spinola A, Fonseca S, et al. Aggressive mature natural killer cell neoplasms: report on a series of 12 European patients with emphasis on flow cytometry based immunophenotype and DNA content of neoplastic natural killer cells. Leuk Lymphoma 2015;56: 103-112.
19 Zaheen A, Delabie J, Vajpeyi R et al. The first report of a previously undescribed EBV-negative NK-cell lymphoma of the GI tract presenting as chronic diarrhoea with eosinophilia. BMJ Case Rep 2015 (e-pub ahead of print).

20 Ryder J, Wang X, Bao L, et al. Aggressive natural killer cell leukemia: report of a Chinese series and review of the literature. Int J Hematol 2007;85:18-25.

21 Matsusaka K, Funata S, Fukayama M, et al. DNA methylation in gastric cancer, related to Helicobacter pylori and Epstein-Barr virus. World J Gastroenterol 2014;20:3916-3926.

22 Kaneda A, Matsusaka K, Aburatani H, et al. EpsteinBarr virus infection as an epigenetic driver of tumorigenesis. Cancer Res 2012;72:3445-3450.

23 Sander S, Bullinger L, Klapproth K, et al. MYC stimulates EZH2 expression by repression of its negative regulator miR-26a. Blood 2008;112:4202-4212.

24 Kaur M, Cole MD. MYC acts via the PTEN tumor suppressor to elicit autoregulation and genome-wide gene repression by activation of the Ezh2 methyltransferase. Cancer Res 2013;73:695-705.

25 Koh CM, Iwata $\mathrm{T}$, Zheng $\mathrm{Q}$, et al. Myc enforces overexpression of EZH2 in early prostatic neoplasia via transcriptional and post-transcriptional mechanisms. Oncotarget 2011;2:669-683.

26 Suva ML, Riggi N, Janiszewska M, et al. EZH2 is essential for glioblastoma cancer stem cell maintenance. Cancer Res 2009;69:9211-9218.

27 Benetatos L, Vartholomatos G, Hatzimichael E. Polycomb group proteins and MYC: the cancer connection. Cell Mol Life Sci 2014;71:257-269.

28 Neri F, Zippo A, Krepelova A, et al. Myc regulates the transcription of the PRC2 gene to control the expression of developmental genes in embryonic stem cells. Mol Cell Biol 2012;32:840-851.

29 Koo GC, Tan SY, Tang T, et al. Janus kinase 3-activating mutations identified in natural killer/T-cell lymphoma. Cancer Discov 2012;2:591-597.

30 Karube K, Nakagawa M, Tsuzuki S, et al. Identification of FOXO3 and PRDM1 as tumor-suppressor gene candidates in NK-cell neoplasms by genomic and functional analyses. Blood 2011;118:3195-3204.

31 Lee S, Park HY, Kang SY, et al. Genetic alterations of JAK/STAT cascade and histone modification in extranodal NK/T-cell lymphoma nasal type. Oncotarget 2015;6:17764-17776.

32 Choi S, Go JH, Kim EK, et al. Mutational analysis of extranodal NK/T-cell lymphoma using targeted sequencing with a comprehensive cancer panel. Genomics Inform 2016;14:78-84.

33 Bouchekioua A, Scourzic L, de Wever O, et al. JAK3 deregulation by activating mutations confers invasive growth advantage in extranodal nasal-type natural killer cell lymphoma. Leukemia 2014;28:338-348.

Supplementary Information accompanies the paper on Modern Pathology website (http://www.nature.com/ modpathol) 